\title{
The home food environment of overweight gatekeepers in the Netherlands
}

\author{
Maartje P Poelman ${ }^{1, *}$, Emely de Vet ${ }^{2}$, Elizabeth Velema ${ }^{1}$, Jacob C Seidell ${ }^{1}$ and \\ Ingrid HM Steenhuis ${ }^{1}$ \\ 'Department of Health Sciences, VU University Amsterdam and EMGO Institute for Health and Care Research, De \\ Boelelaan 1085, 1081 HV Amsterdam, The Netherlands: ${ }^{2}$ Wageningen University and Research Centre, \\ The Netherlands. Department of Social Sciences, sub-department Communication, Philosophy and Technology: \\ Centre for Integrative Development. Chairgroup Strategic Communication
}

Submitted 24 March 2014: Final revision received 17 June 2014: Accepted 16 September 2014: First published online 31 October 2014

\begin{abstract}
Objective: The aim of the present study was to gain insight into (i) processed snackfood availability, (ii) processed snack-food salience and (iii) the size of dinnerware among households with overweight gatekeepers. Moreover, associations between gatekeepers' characteristics and in-home observations were determined.

Design: A cross-sectional observation of home food environments was conducted as part of a baseline measurement of a larger study.

Setting: Home food environments of overweight and obese gatekeepers in the Netherlands.

Subjects: Household gatekeepers ( $n$ 278). Mean household size of the gatekeepers was 3.0 (SD 1.3) persons. Mean age of the gatekeepers was 45.7 (SD 9.2) years, $34.9 \%$ were overweight and $65.1 \%$ were obese. Of the gatekeepers, $20.9 \%$ had a low level of education and $42.7 \%$ had a high level of education.

Results: In $70 \%$ of the households, eight or more packages of processed snack foods were present. In $54 \%$ of the households, processed snack foods were stored close to non-processed food items and in $78 \%$ of households close to non-food items. In $33 \%$ of the households, processed snack foods were visible in the kitchen and in $15 \%$ of the households processed snack foods were visible in the living room. Of the dinnerware items, 14\% (plates), $57 \%$ (glasses), $78 \%$ (dessert bowls), $67 \%$ (soup bowls) and $58 \%$ (mugs) were larger than the reference norms of the Netherlands Nutrition Centre Foundation. Older gatekeepers used significantly smaller dinnerware than younger gatekeepers.

Conclusions: Environmental factors endorsing overconsumption are commonly present in the home environments of overweight people and could lead to unplanned eating or passive overconsumption.
\end{abstract}

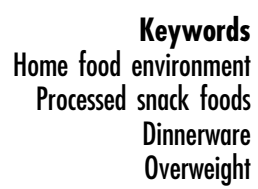

In recent years, the modern food environment has been associated with increased energy intake and the increased prevalence of overweight and obesity ${ }^{(1)}$. An important setting that influences eating behaviour and dietary intake is the home food environment ${ }^{(2)}$. The home food environment is the place where the retail food environment interacts with actual food intake ${ }^{(3)}$.

In the Netherlands, the majority of the meals are consumed at home ${ }^{(4)}$ and this pattern is more common compared with other countries ${ }^{(5)}$. Although dining out has become more common among Dutch individuals (in 1997, $29 \%$ of individuals visited a restaurant once monthly or more often; in 2011 this percentage was $35 \%)^{(6)}$, the home food environment is fundamental in the development of food preferences and consumption habits ${ }^{(7,8)}$. The present study is focused on the physical home food environment, which refers to what is present in the home ${ }^{(9)}$.

Several factors in the physical home food environment have been associated with a surplus energy intake ${ }^{(10-13)}$, particularly the presence of processed snack foods (e.g. cookies, chips), processed snack-food salience and the size of dinnerware. In terms of the presence of processed snack foods (hereafter referred to as 'snack foods' or 'snacks'), we refer to the actual availability of these snacks in the home environment. Previous studies have illustrated the interdependence of home food availability and intake of both unhealthy (e.g. soft drinks, snack foods) ${ }^{(14-16)}$ and healthy (e.g. fruit and vegetables) foods ${ }^{(16-19)}$. Snack-food salience refers to the prominence of these foods in the home environment. For example, snacks foods may 
become salient due to an unbeneficial way of stockpiling food (e.g. stored close to regularly used items such as dishware) or because they are visible in parts of the home where people often encounter them (e.g. a bowl of chocolates placed prominently on the coffee table). The salience of snack foods evokes individuals' desire to eat, prompts their desire to consume larger amounts and increases the actual amount they consume ${ }^{(11,20,21)}$. It is also suggested that food salience might lead to eating food that was unintended $^{(22)}$. For example, people might be confronted with snack foods during food-related (e.g. preparing dinner) or non-food related (e.g. cleaning, television viewing) activities, possibly resulting in unintended eating. Previous studies suggested that the storage of foods at visible places increased individuals' consumption rates, consumption frequencies and the amount of food consumed. Especially for high-convenience processed foods (foods that require minimal preparation; e.g. snack foods), the frequency and quantity of consumption increase when the stockpile of such foods is visible ${ }^{(23)}$. People often start eating without deliberate decision making but in response to exposure to foods, which increases the likelihood of eating and keeps cueing people to continuing eating, resulting in an increased risk for overconsumption ${ }^{(10,11)}$. A third relevant factor in the home food environment that may influence energy intake is dinnerware size. In many countries, the majority of food is consumed by using dinnerware $^{(24)}$ and the size of dinnerware (e.g. bowls) is positively associated with energy intake, although studies that have examined the association between plate size and energy intake have shown mixed results ${ }^{(25-27)}$. Larger dinnerware has more food capacity ${ }^{(28)}$ and by using larger dinnerware the norm seems to shift towards larger amounts as an appropriate amount to serve $\mathrm{e}^{(29,30)}$. A study that used mathematical modelling to estimate the influence of dinnerware size on energy intake indicated that small increases in dishware (plates and bowls) could lead to a substantial increase in energy intake ${ }^{(31)}$. For example, when comparing the energy content of a meal with an average energy density $(670 \mathrm{~kJ} / 100 \mathrm{~g})$, the energy content $(2536 \mathrm{~kJ})$ of the meal served on a plate of 11 inches $(\sim 28 \mathrm{~cm})$ was $929 \mathrm{~kJ}(221.2 \mathrm{kcal})$ higher than the energy content (1607 kJ) of the similar meal served on a plate of 9 inches $(\sim 23$ $\mathrm{cm})^{(31)}$. A few studies have also demonstrated the actual effect of dinnerware size on portion-size selection ${ }^{(13,30)}$. For example, a laboratory study indicated that people served themselves $31 \%$ more ice cream from a bowl that was $50 \%$ larger and $14.5 \%$ more when the spoon they used was 33\% larger ${ }^{(13)}$. For plate size, some studies have suggested a plate-size effect on energy intake ${ }^{(12,32)}$ whereas other studies have not ${ }^{(25,27)}$. Nevertheless, the use of smaller dinnerware (also plates) is advised by governmental campaigns as a weight-management method $^{(33)}$.

Many educational weight-loss interventions for overweight and obese individuals have been developed and evaluated $^{(34)}$. Overweight and obese individuals profit from losing weight because this results in major health benefits ${ }^{(35)}$. For a long period of time, interventions have focused only on changing individual behaviours but in recent times, more attention has been directed to the importance of improving the food environment ${ }^{(2,36)}$. As stated previously, the availability of snack foods, the unbeneficial way of stockpiling snack foods, the visibility of snack foods and large-sized dinnerware are associated with overconsumption and could be targeted as part of a weight-loss intervention with a home environmental focus. Although these factors are expected to be present in real-life physical home food environments, the extent to which these factors are currently present is unknown. Such insight is important because it provides information about whether there is still room for improvement.

The main aim of the present descriptive observational study among households with overweight gatekeepers was to gain insight into: (i) processed snack-food availability; (ii) processed snack-food salience (in-home storage and visibility of snack foods); and (iii) size of dinnerware. The secondary aim was to identify the associations between gatekeepers' characteristics and snack-food availability, snack-food salience and size of dinnerware.

\section{Methods}

\section{Study design and procedure}

A cross-sectional study was conducted, which was integrated as part of the baseline measurement of a larger study to evaluate the effect of an educational intervention aimed at portion sizes among overweight and obese individuals ${ }^{(37)}$. For the larger study, overweight and obese household gatekeepers were eligible to participate. Household gatekeepers were defined as 'the family member most responsible for buying groceries and preparing dinner'. Main inclusion criteria were a BMI above $25 \mathrm{~kg} / \mathrm{m}^{2}$, age between 18 and 60 years, not being on a diet, not visiting a dietitian and not reporting to be or to have been in an intensive weight-loss treatment. Strategies for the recruitment of the gatekeepers included distributing information letters to general practitioners; advertisements in local newspapers; messages on local radio stations; and distributing flyers and posters in pharmacies, public facilities and the waiting rooms of willing physiotherapists and general practitioners.

Of the 617 participants who registered for participation, a total of 278 ( $45 \%$ ) adults fulfilled the inclusion criteria. For the present study, the home food environments of these 278 overweight gatekeepers were observed. Participants were visited at home on appointment by one of the researchers (M.P.P. or E.V.). Previous to the appointment, written informed consent of the participants was obtained. The study was approved by the Medical Ethical Committee of the VU Medical Centre Amsterdam.

During the home visit, objectively measured height and weight of the participants were assessed. After that, the 
homes were screened for snack availability, snack salience (way of snack storage and snack visibility) and the size of dinnerware used. The participants assisted the researchers and were present during all in-home measures. Participants were asked if they could show where they stored the food in their home. During this time, the researchers screened the home environment for snack availability and snack salience. After viewing the house, participants were asked to get the dinnerware that they used most often in order to measure the size of the dinnerware.

\section{Measures}

\section{Gatekeeper characteristics}

To get an indication of the background of the households, demographic information was obtained from each gatekeeper and included age, nationality, educational level and BMI. Education was based on highest qualification attained and was classified into three groups: low ('those with less than secondary school or an A-level certificate'), middle ('those with A-levels or Dutch A-level equivalent (VWO) graduation certificate') and high ('those with polytechnic or university degrees'). Objective BMI (weight in kilograms divided by the square of height in metres) was determined by measuring each gatekeeper's weight (using a Marsden MPMS-250 digital scale, Oxfordshire, UK), in light clothes and with shoes removed, and height (using a SECA 214 portable stadiometer, Hamburg, Germany).

\section{Household size}

Household size was determined by counting the number of family members permanently living in the house.

\section{Availability of snack foods}

The availability (yes $=1$, no $=0$ ) of processed savoury and sweet snack foods was verified. Snack foods of the following categories were verified: biscuits, cake, candies (hard/soft candies), cookies, doughnuts, pastries, pies, popcorn, chocolate (bars, bonbons), muesli/grain bars, processed nuts, chips, nachos, cheese biscuits, rice snacks, and processed meat or poultry snack-food sticks. Moreover, to get an indication of the amount of snack foods available, the total number of packages of savoury and sweet processed snack foods was calculated. For savoury snacks and sweets, each package regardless of weight was counted as one package, except for single-serve or $418 \mathrm{~kJ}$ $(100 \mathrm{kcal})$ packages. When four or more single-serve or $418 \mathrm{~kJ}$ (100 kcal) packs were present, they were scored as one package. Also, containers or jars containing savoury snacks or sweets (without the package) were counted as one package. Products stored in the freezer compartment (e.g. ice cream, frozen snacks) were not taken into account for practical reasons (getting everything out of the compartment, freezer not in the kitchen).

\section{Snack storage}

To assess the way of stockpiling of snack foods, it was determined if savoury and/or sweet snack foods were stored close (in the same cabinet, drawer) to non-snack foods (i.e. bread, spaghetti; yes $=1$, no $=0$ ) or other household items (i.e. plates, cleaning equipment; yes $=1$, no $=0$ ). This was determined because people might be confronted with the snack foods during food-related (e.g. preparing dinner) or non-food related (e.g. cleaning) activities, increasing the risk of unplanned eating.

\section{Visibility of snack foods}

Because people often start eating without deliberate decision making but in response to exposure to foods, it was determined if people were exposed (yes $=1$, no $=0$ ) to visible savoury and/or sweet snack foods in the living room or the kitchen.

\section{Size of dinnerware}

The volume/size of dinnerware was determined for five dinnerware items. The volume of mugs, glasses, soup bowls and dessert bowls was measured by determining the volume of water in millilitres to $1 \mathrm{~cm}$ below the edge. Although previous studies showed mixed results on the effect of plate size on portion-size perception and energy intake ${ }^{(12,25-27)}$, we did take the measurement of dinner plate size into account. In doing so, the diameter in centimetres of dinner plates was measured using a tape measure. If the gatekeepers used more than one dinnerware item frequently (i.e. two types of glasses are frequently used for soft drinks), the average size of the items was used.

\section{Statistical analysis}

Descriptive statistics were used to summarize gatekeeper characteristics (BMI, age, nationality and educational level). Household size was categorized as: (i) 1-person household; (ii) 2- or 3-person household; or (iii) $\geq 4$-person household. To determine the availability of savoury and sweet processed snack foods, the percentages of households that stocked savoury snack foods (yes/no) and sweet snack foods (yes/no) were determined. In addition, the percentages of households that had no snack foods, one type of snack food or both types of snack foods were calculated. To get insight in the availability of snack foods, four availability categories were created: (i) $\leq 3$ packages; (ii) 4-7 packages; (iii) 8-15 packages; and (iv) $\geq 16$ packages

The way of snack storage was determined by the percentages of households in which savoury and sweet snack foods were stored in the presence of other household items (\% yes/no) or non-snack foods (\% yes/no). To explore snack visibility, the percentages of households in which there was an exposure of the savoury or sweet snack foods in the kitchen or living room (\% yes/no) were calculated.

For dinnerware, descriptive statistics (mean, standard deviation) of the size (plate; centimetres) or the volume (bowls, glass, mug; millilitres) were determined. As there 
is no consensus yet about 'small' or 'large' dinnerware and its effect on energy intake for most dinnerware, standard dinnerware sizes ('reference sizes') according the Netherlands Nutrition Centre Foundation were used to discriminate between the dinnerware items ${ }^{(38)}$. The reference size was $200 \mathrm{ml}$ for mugs, $250 \mathrm{ml}$ for soup bowls and $150 \mathrm{ml}$ for dessert bowls. To account for different sizes of glasses for non-alcoholic drinks $(150 \mathrm{ml}$ and $250 \mathrm{ml}$ ), a mean reference size of $200 \mathrm{ml}$ was used. To determine commonly used sizes of dinnerware, categories ('small', 'medium', 'large' and 'extra large') were developed based on these reference sizes. For mugs, glasses, soup bowls and dessert bowls, a margin of $\pm 10 \%$ of the reference size was used to define the dinnerware items as the 'reference dinnerware size' and corresponded to the category 'medium'. Dinnerware items sized lower than the reference size were indicated as 'small' ( $<-10 \%$ deviance from reference size). Dinnerware items that were $50 \%$ or more than the reference dinnerware size were considered 'extra large'. All sizes between 'medium' and 'extra large' was categorized as 'large' ( $>+10 \%$ and $<+50 \%$ deviance from reference size). Percentages of households that used dinnerware within each category were calculated.

For dinner plates, no standard sizes exist. Therefore, plate size $(26.4 \mathrm{~cm})$ from a previous study ${ }^{(12)}$ and size of dinner plates frequently used in the Netherlands ${ }^{(39)}$ were considered to define the 'reference size' of $26 \mathrm{~cm}$ for dinner plates. Also plate sizes were categorized as 'small', 'medium', 'large' or 'extra large', although different margins were needed because: (i) different measurement units were used (centimetres instead of millilitres); and (ii) the variance in measurement was smaller compared with other forms of dinnerware. Therefore, a $5 \%$ margin of the reference size was used to define a 'medium' plate size and a margin of $10 \%$ of the reference size or above was considered 'extra large'. Dinner plates sized lower than the reference size were indicated as 'small' ( $<-5 \%$ deviance from reference size). All sizes between 'medium' and 'extra large' were categorized as 'large' $(>+5 \%$ and $<+10 \%$ deviance from reference size). Percentages of households that used plates within each category were calculated.

To identify the associations between gatekeeper characteristics and snack availability, snack-food salience and size of dinnerware, multiple logistic or linear regression with all gatekeeper characteristics (BMI (continuous), age (continuous), educational level (low, middle, high)) and household size (one person, two to three persons, four or more persons) as independent variables and snack-food availability (number of packages), snack storage and snack visibility as dependent variables were conducted. Nationality was not included in the analyses as only $3.2 \%$ of the participants had a nationality 'other than Dutch' and thus was not reliable to provide insight into the associations between nationality and the home environment. All analyses were conducted using the statistical software package IBM SPSS Statistics 21:0·0.

\section{Results}

\section{Gatekeeper characteristics}

The mean age of the gatekeepers was $45 \cdot 7$ (SD 9.2) years and ranged from 23 to 60 years; almost all gatekeepers (96.8\%) had Dutch nationality. Of the gatekeepers, $20.9 \%$ had a low level of education, $36.4 \%$ had a middle level of education and $42.7 \%$ had a high level of education. Compared with the general Dutch population, more participants in the present study had a high educational level $(+11 \%)$ and fewer participants had a low educational level $(-6 \%)^{(40)}$. The mean BMI of the gatekeepers was $32.4(\mathrm{sD} 4.8) \mathrm{kg} / \mathrm{m}^{2}$ (range $25 \cdot 1-53.3 \mathrm{~kg} / \mathrm{m}^{2}$ ) and $34.9 \%$ were overweight and $65.1 \%$ were obese. Therefore, the associations between BMI and home environmental factors as described below are applicable only to an overweight study sample.

\section{Housebold size}

The average household size was 3.0 (SD 1.3) persons (range 1-7 persons). Of the included households, 10.5\% consisted of one person, $49.6 \%$ had two or three household members, and $39.9 \%$ consisted of four or more household members.

\section{Availability of snack foods}

In $79.1 \%$ of the home food environments, savoury snack foods were available and in a larger percentage of $95.3 \%$ of the households, sweet snack foods were present. In only $1.8 \%$ of the households ( $n$ 5) were no savoury or sweet snack foods available, whereas in $76.3 \%$ of the households both types of snack foods were available. In the households where snacks were present (98.2\%), the mean number of available packages of savoury snacks was 4 (SD 4) and for sweets this number was 8 (SD 7). Overall, households had on average more sweet snacks than savoury snacks available (Table 1). In $70 \%$ of the households, eight or more packages of snacks were available, of which $30 \%$ had even sixteen or more packages of both savoury and sweet snacks present. Family size was positively associated with the overall available number of sweet and savoury snack-food packages. After correction for age, educational level and BMI, 2- or 3-person households $(B=4.02$, $\mathrm{SE}=1.86, P=0.03)$ and $\geq 4$-person households $(B=7 \cdot 64$, $\mathrm{SE}=1 \cdot 89, P<0 \cdot 01)$ had significantly more packages available compared with 1-person households. No significant associations for BMI, age and educational level were found (Table 2).

\section{Snack-food storage}

In $54 \%$ of the households, savoury or sweet snack foods were stored close to non-snack foods. In $78 \%$ of the households, snack foods were stored close to other household or non-food items. In $41.5 \%$ of the households, snack foods were stored in both places; whereas in $11.6 \%$ these snack foods were not stored close at all to other 
Table 1 Number of sweet and savoury processed snack foods available in Dutch households of overweight and obese gatekeepers

\begin{tabular}{|c|c|c|c|c|c|c|}
\hline \multirow[b]{3}{*}{ Category margins } & \multicolumn{6}{|c|}{ Processed snack-food type } \\
\hline & \multicolumn{2}{|c|}{ Sweet snacks } & \multicolumn{2}{|c|}{ Savoury snacks } & \multicolumn{2}{|c|}{ Overall snacks } \\
\hline & $n$ & $\%$ & $n$ & $\%$ & $n$ & $\%$ \\
\hline$\leq 3$ packages & 66 & 25 & 110 & 50 & 21 & 10 \\
\hline $4-7$ packages & 77 & 29 & 74 & 34 & 45 & 20 \\
\hline $8-15$ packages & 87 & 33 & 33 & 15 & 84 & 38 \\
\hline$\geq 16$ packages & 35 & 13 & 3 & 1 & 70 & 32 \\
\hline
\end{tabular}

Table 2 Multivariate linear regression analysis of household characteristics on snack-food availability in Dutch households of overweight and obese gatekeepers

\begin{tabular}{|c|c|c|c|c|}
\hline & \multicolumn{4}{|c|}{ Snack-food availability (number of packages) } \\
\hline & $B$ & SE & $95 \% \mathrm{Cl}$ & $P$ \\
\hline Educational level (middle) & -0.71 & 1.51 & $-3 \cdot 68,2 \cdot 26$ & 0.64 \\
\hline Educational level (high) & -0.84 & 1.46 & $-3.72,2.04$ & 0.56 \\
\hline $\mathrm{BMI}^{\star}$ & -0.06 & 0.12 & $0.61,-0.29$ & 0.61 \\
\hline Age & 0.003 & 0.06 & $-0.12,0.12$ & 0.96 \\
\hline 2 or 3 household members & 4.02 & 1.86 & $0.36,7.68$ & 0.03 \\
\hline$\geq 4$ household members & $7 \cdot 64$ & 1.89 & $3.90,11.37$ & $<0.001$ \\
\hline
\end{tabular}

*Only participants with a BMl above $25 \mathrm{~kg} / \mathrm{m}^{2}$ were included in the study.

Table 3 Multivariate logistic regression analysis of household characteristics on snack-food storage and snackfood visibility in Dutch households of overweight and obese gatekeepers

\begin{tabular}{|c|c|c|c|}
\hline & $\begin{array}{c}\text { OR } \\
(\exp B)\end{array}$ & $95 \% \mathrm{Cl}$ & $P$ \\
\hline \multicolumn{4}{|c|}{ Snack-food storage (stored close to non-snack foods) } \\
\hline Educational level (middle) & 0.97 & $0.37,2.56$ & 0.95 \\
\hline Educational level (high) & 0.43 & $0.18,1.04$ & 0.06 \\
\hline $\mathrm{BMI}^{*}$ & 0.99 & $0.92,1.06$ & 0.75 \\
\hline Age & 1.02 & $0.98,1.05$ & 0.36 \\
\hline 2 or 3 household members & 0.72 & $0.24,2 \cdot 10$ & 0.53 \\
\hline$\geq 4$ household members & 1.42 & $0.45,4.44$ & 0.55 \\
\hline \multicolumn{4}{|c|}{ Snäk-food storage (stored close to non-food items) } \\
\hline Educational level (middle) & 0.88 & $0.43,1.79$ & 0.72 \\
\hline Educational level (high) & 0.73 & $0.37,1.45$ & 0.37 \\
\hline $\mathrm{BMI}^{*}$ & 0.99 & $0.94,1.05$ & 0.78 \\
\hline Age & 1.02 & $0.99,1.05$ & 0.19 \\
\hline 2 or 3 household members & 1.49 & $0.62,3.58$ & 0.38 \\
\hline$\geq 4$ household members & 2.07 & $0.84,5.06$ & 0.11 \\
\hline \multicolumn{4}{|c|}{ Visibility of snack foods in kitchen } \\
\hline Educational level (middle) & 1.93 & $0.92,4.08$ & 0.08 \\
\hline Educational level (high) & 0.96 & $0.45,2.03$ & 0.92 \\
\hline $\mathrm{BMI}^{*}$ & 1.00 & $0.95,1.06$ & 0.98 \\
\hline Age & 0.99 & $0.96,1.02$ & 0.51 \\
\hline 2 or 3 household members & $1 \cdot 13$ & $1.13,0.45$ & 2.84 \\
\hline$\geq 4$ household members & $1 \cdot 12$ & $0.44,2.86$ & 0.81 \\
\hline \multicolumn{4}{|c|}{ Visibility of snack foods in living room } \\
\hline Educational level (middle) & $1 \cdot 11$ & $0.43,2.80$ & 0.83 \\
\hline Educational level (high) & 0.57 & $0.22,1.52$ & 0.26 \\
\hline $\mathrm{BMI}^{*}$ & 1.02 & $1.02,0.94$ & 1.09 \\
\hline Age & 1.02 & $1.02,0.98$ & 1.07 \\
\hline 2 or 3 household members & 0.50 & $0.20,1.72$ & 0.33 \\
\hline$\geq 4$ household members & 0.50 & $0.16,1.56$ & 0.23 \\
\hline
\end{tabular}

*Only participants with a BMl above $25 \mathrm{~kg} / \mathrm{m}^{2}$ were included in the study.

household or non-food items. No significant associations for BMI, age, educational level, household size and snackfood availability were found (Table 3).

\section{Visibility of snack foods}

In $33 \%$ of the households, snack foods were visible in the kitchen and in $15 \%$ snack foods were visible in the 
living room. In a small percentage of households (6.8\%), snack foods were visible in both the kitchen and the living room. However, in the majority of households, snack foods were not visible at all (59.4\%). BMI, age, educational level and household size were not associated with visibility of snacks in the living room or the kitchen (Table 3).

\section{Size of dinnerware}

The size and volumes of the dinnerware varied greatly among the households; the greatest variation was found for soup bowls with a difference of $600 \mathrm{ml}$ between the smallest $(150 \mathrm{ml})$ and the largest $(750 \mathrm{ml})$ observation. Only in $2 \%$ of the households in which all five dinnerware items were measured ( $n$ 184) were all items smaller than or comparable to the reference size. In $4 \%$ of the households, all dinnerware items were above the reference size. Except for plates, the majority of households used dinnerware that was categorized as 'large'. The most common plates among the households (56\%) were 'medium' in size. The 'extra large' dinnerware category was most frequently represented for soup bowls (28\%) and dessert bowls (25\%; Table 4).

Multiple linear regression (Table 5) showed that, compared with low educated people, high educated people used statistically significantly bigger plates $(B=0.77$, $\mathrm{SE}=0 \cdot 31, P=0 \cdot 01)$. BMI was negatively associated with plate size $(B=-0.06$, sE $=0.03, P=0 \cdot 02)$, demonstrating that people with a higher BMI use smaller plates. Age was negatively associated with the volume of soft-drink glasses, dessert bowls and mugs (Table 5), indicating that in households of older gatekeepers smaller dessert bowls, mugs and soft-drink glasses were used. Finally, household size was negatively associated with dessert-bowl size ( 2 or 3 family members: $B=-38.54, \mathrm{sE}=18.07, P=0.03$ and $\geq 4$ family members: $B=-43 \cdot 17, \mathrm{sE}=18 \cdot 48, P=0 \cdot 02$ ), indicating that in households with more family members smaller bowls for dessert are used. No other significant associations were found.

\section{Discussion}

The present study sought to observe whether physical home food environment factors that may stimulate overconsumption were actually present in the homes of overweight household gatekeepers. The findings can be summarized as follows. First, in a large majority of the visited households (76\%) sweet and savoury snack foods were present and in the majority of households (70\%) eight or more packages of processed snack foods were available, of which $30 \%$ of the households had sixteen or more packages available. Second, in more than half of the households, snack foods were closely stored in the presence of non-snack foods and in more than two-thirds of the households in the presence of non-food items. In a third of the households, snack foods were stored visibly in the kitchen whereas this was $15 \%$ in the living room. Third, with the exception of plates, most of the dinnerware
Table 4 Size of dishware used in Dutch households of overweight and obese gatekeepers

\begin{tabular}{|c|c|c|c|}
\hline $\begin{array}{l}\text { Dinnerware/category } \\
(\mathrm{S}, \mathrm{M}, \mathrm{L}, \mathrm{XL})^{\star}\end{array}$ & Category margins & $n$ & $\%$ \\
\hline Plates $(\mathrm{cm}) \dagger$ & & \multicolumn{2}{|c|}{275} \\
\hline$S$ & $<24.7$ & 83 & 30 \\
\hline M (ref.) & $\geq 24.7$ to $\leq 27.3$ & 154 & 56 \\
\hline $\mathrm{L}$ & $>27.3$ to $<28.6$ & 35 & 13 \\
\hline$X L$ & $\geq 28.6$ & 3 & 1 \\
\hline Glasses (ml)‡ & & \multicolumn{2}{|c|}{265} \\
\hline $\mathrm{S}$ & $<180$ & 44 & 17 \\
\hline M (ref.) & $\geq 180$ to $\leq 220$ & 69 & 26 \\
\hline $\mathrm{L}$ & $>220$ to $<300$ & 108 & 40 \\
\hline$X L$ & $\geq 300$ & 44 & 17 \\
\hline Soup bowl (ml)‡ & & \multicolumn{2}{|c|}{240} \\
\hline S & $<225$ & 22 & 9 \\
\hline M (ref.) & $\geq 225$ to $\leq 275$ & 58 & 24 \\
\hline $\mathrm{L}$ & $>275$ to $<375$ & 93 & 39 \\
\hline$X L$ & $\geq 375$ & 67 & 28 \\
\hline Dessert bowl (ml)‡ & & \multicolumn{2}{|c|}{233} \\
\hline $\mathrm{S}$ & $<135$ & 13 & 6 \\
\hline M (ref.) & $\geq 135$ to $\leq 165$ & 40 & 17 \\
\hline $\mathrm{L}$ & $>165$ to $<275$ & 123 & 53 \\
\hline$X L$ & $\geq 275$ & 57 & 25 \\
\hline Mugs (ml)‡ & & \multicolumn{2}{|c|}{254} \\
\hline S & $<180$ & 33 & 13 \\
\hline M (ref.) & $\geq 180$ to $\leq 220$ & 74 & 29 \\
\hline $\mathrm{L}$ & $>220$ to $<300$ & 116 & 46 \\
\hline$X L$ & $\geq 300$ & 31 & 12 \\
\hline
\end{tabular}

*Dinnerware categories: S, small; M (ref.), medium and reference category; $\mathrm{L}$, large; $\mathrm{XL}$, extra large.

†M (ref.) category is reference dinner plate size $(26 \mathrm{~cm}) \pm 5 \%$. $X \mathrm{~L}$ is $>10 \%$ of the reference dinner plate size.

$\ddagger \mathrm{M}$ (ref.) category is reference dinnerware size (glass $(200 \mathrm{ml})$; soup bowl $(250 \mathrm{ml})$; dessert bowl $(150 \mathrm{ml})$; mug $(200 \mathrm{ml})) \pm 10 \%$. XL is $>50 \%$ of the reference dinnerware size.

used was larger than the reference dinnerware sizes indicated by the Netherlands Nutrition Centre Foundation $^{(38)}$ and categorized as 'large'. In only $2 \%$ of the households was dinnerware consistent with the reference dinnerware sizes.

Secondary findings revealed that in households of older gatekeepers, significantly smaller dessert bowls, mugs and glasses were used as compared with households belonging to younger gatekeepers. This finding is in line with an earlier study regarding the association between age and portion size that indicated that older chefs served smaller portions than their younger colleagues ${ }^{(41)}$. People with a higher BMI used statistically significantly smaller plates. However, plates were only $0.06 \mathrm{~cm}$ larger per BMI increase of $1 \mathrm{~kg} / \mathrm{m}^{2}$, a difference that is hardly visible. Nevertheless, a possible explanation for the finding that obesity is negatively associated with plate size is that obese individuals are already more aware of the effect of plate size on energy intake, as this is highlighted by governmental campaigns as a weight-management method for example ${ }^{(33)}$. In addition, high educated gatekeepers used significantly larger plates than middle and lower educated gatekeepers, although this difference was also less than a centimetre. However, it could be that high educated gatekeepers visit restaurants, where large plates are rather 
Table 5 Multivariate linear regression analysis of household characteristics on dinnerware size in Dutch households of overweight and obese gatekeepers

\begin{tabular}{|c|c|c|c|c|}
\hline Dinnerware item and variables & $B(\mathrm{ml})$ & SE & $95 \% \mathrm{Cl}$ & $P$ \\
\hline \multicolumn{5}{|l|}{ Mugs } \\
\hline Educational level (middle) & $1 \cdot 70$ & $8 \cdot 20$ & $-14 \cdot 46,17 \cdot 85$ & 0.84 \\
\hline Educational level (high) & -4.49 & 7.94 & $-20 \cdot 13,11 \cdot 16$ & 0.57 \\
\hline $\mathrm{BMI}^{*}$ & -0.091 & 0.63 & $-1.33,1.15$ & 0.89 \\
\hline Age & -1.41 & 0.33 & $-2.06,-0.76$ & 0.00 \\
\hline 2 or 3 household members & $2 \cdot 75$ & $10 \cdot 10$ & $-17 \cdot 06,22 \cdot 56$ & 0.79 \\
\hline$\geq 4$ household members & $-15 \cdot 10$ & $10 \cdot 23$ & $-35 \cdot 26,5 \cdot 05$ & 0.14 \\
\hline \multicolumn{5}{|l|}{ Soup bowls } \\
\hline Educational level (middle) & 14.94 & $16 \cdot 39$ & $-17 \cdot 36,47 \cdot 24$ & 0.36 \\
\hline Educational level (high) & $19 \cdot 04$ & $15 \cdot 87$ & $-12 \cdot 25,50 \cdot 32$ & 0.23 \\
\hline $\mathrm{BMI}^{*}$ & -0.41 & 1.33 & $-3.02,2.20$ & 0.76 \\
\hline Age & -0.95 & 0.68 & $-2.30,0.39$ & 0.16 \\
\hline 2 or 3 household members & -33.77 & 22.41 & $-77 \cdot 95,10 \cdot 41$ & 0.13 \\
\hline$\geq 4$ household members & -21.5 & $22 \cdot 54$ & $-65.94,22.91$ & 0.34 \\
\hline \multicolumn{5}{|l|}{ Dessert bowls } \\
\hline Educational level (middle) & $-11 \cdot 77$ & 14.44 & $-40 \cdot 24,16 \cdot 70$ & 0.42 \\
\hline Educational level (high) & $-17 \cdot 81$ & $14 \cdot 16$ & $-45 \cdot 74,10 \cdot 11$ & 0.21 \\
\hline $\mathrm{BMI}^{*}$ & -1.41 & $1 \cdot 11$ & $-3.58,0.77$ & 0.20 \\
\hline Age & $-2 \cdot 19$ & 0.58 & $-3.34,-1.03$ & 0.00 \\
\hline 2 or 3 household members & -38.54 & 18.07 & $-74 \cdot 16,-2.92$ & 0.03 \\
\hline$\geq 4$ household members & $-43 \cdot 17$ & 18.48 & $-79.59,-6.75$ & 0.02 \\
\hline \multicolumn{5}{|l|}{ Glāsses } \\
\hline Educational level (middle) & $-2 \cdot 96$ & $10 \cdot 32$ & $-23.29,17.37$ & 0.78 \\
\hline Educational level (high) & -6.97 & $10 \cdot 03$ & $-26 \cdot 73,12 \cdot 79$ & 0.49 \\
\hline $\mathrm{BMI}^{*}$ & 1.31 & 0.81 & $-0.29,2.91$ & 0.11 \\
\hline Age & -1.82 & 0.43 & $-2.66,-0.98$ & 0.00 \\
\hline 2 or 3 household members & $13 \cdot 20$ & $12 \cdot 84$ & $-12.09,38.50$ & 0.31 \\
\hline$\geq 4$ household members & 0.55 & $13 \cdot 14$ & $-25 \cdot 34,26 \cdot 45$ & 0.97 \\
\hline \multicolumn{5}{|l|}{ Dinner plates } \\
\hline Educational level (middle) & 0.62 & 0.32 & $-0.02,1.25$ & 0.06 \\
\hline Educational level (high) & 0.77 & 0.31 & $0.16,1.38$ & 0.01 \\
\hline $\mathrm{BMI}^{*}$ & -0.06 & 0.03 & $-0.11,-0.01$ & 0.02 \\
\hline Age & -0.02 & 0.01 & $-0.05,0.01$ & 0.11 \\
\hline 2 or 3 household members & 0.42 & 0.40 & $-0.36,1.20$ & 0.30 \\
\hline$\geq 4$ household members & 0.65 & 0.17 & $-0.15,1.44$ & 0.11 \\
\hline
\end{tabular}

*Only participants with a BMl above $25 \mathrm{~kg} / \mathrm{m}^{2}$ were included in the study.

the norm than the exception, and use plates conforming to this norm at home. However, we have no data to confirm these assumptions. Finally, households with more members used smaller dessert bowls compared with single-person households. Possible explanations are that larger households probably include more children whose energy needs are lower. Another possibility is that when using smaller bowls, multi-serving pre-packed deserts are easier to share.

Several limitations should be noted. Only households of families with at least one overweight or obese member were included. Therefore, the outcomes are not representative for all Dutch home food environments and future research should provide insight in the home food environment of healthy-weight gatekeepers. Another limitation is the crosssectional character of the study and that we did not measure the association between the factors and actual food intake. It could be that foods were accidentally visible at the time of our visit. Furthermore, a crude measure was used to determine the amount of available snacks. Therefore, the figures provide a rather general indication than a precise estimation and the results need to be interpreted with caution. A key strength of this research was the use of direct observation by the researchers to assess products within the households. Another advantage was that new aspects of the physical home food environment were determined.

It is difficult to compare our findings directly with the results of other studies that measured the home food environment because most studies screened different aspects of the home food environment than we observed. However, the present study highlights the importance of the organization of the home food environment, particularly in the way people store and place their foods, and of the dinnerware used. So far, only a few home studies have measured comparable features of the home food environment. For example, in a previous study it was determined if fruit (juice) and vegetables were available in a form or location that facilitated their consumption (e.g. ready-to-eat carrot sticks on the front of a refrigerator shelf) ${ }^{(17)}$. Also some intervention studies have focused on the physical home food environment. For example, interventions provided individuals with serving-size-appropriate dishware ${ }^{(42)}$ or interventions encouraged participants to increase the in-home availability of healthy foods ${ }^{(42-44)}$ or prevented the in-home availability of unhealthy foods ${ }^{(45)}$. 
Although the present study is descriptive in nature, the data may provide important reference information for future studies on home food environments. To give an example, in the current study Dutch dinnerware items were measured and categorized according to Dutch reference sizes. To determine cultural differences, it would be interesting to determine what the size of dinnerware items is in other countries. Another important target for future research is the measurement of the home environmental factors in homes of a gatekeeper with a healthy weight. In doing so, better assumptions regarding the association between the factors and weight status can be drawn. Moreover, additional measures of the physical home food environment could be taken into account. For example, the availability of sugar-sweetened beverages or the visibility of healthy foods (e.g. fruit) in the kitchen or living room could be determined. Also the availability of snacks can be evaluated by more precisely; for example, by determining the amount of snacks available by weighing.

\section{Conclusion}

Physical home food environmental factors regarding the way of stockpiling snack foods and to a lesser extent the visibility of snack foods are present in the real-life home food environments of overweight and obese gatekeepers. In $70 \%$ of the households more than eight packages of processed snack foods were present and also the size of dinnerware exceeded the predefined reference sizes among the majority of the households. Noticeable was the larger dinnerware used by younger gatekeepers. Interventions addressing these factors may help individuals to eliminate the influences of snack-food availability, the unfavourable way of stockpiling snack foods, the visibility of snack foods and the use of large dinnerware within their homes. In doing so, controlling energy intake may be more easily accomplished.

\section{Acknowledgements}

Acknowledgements: The authors wish to thank the participants for their study participation. Financial support: This study was funded by ZonMw, the Dutch Organization for Health Research and Development (project number 121020019). ZonMw had no role in the design, analysis or writing of this article. Conflict of interest: None. Authorship: All authors were responsible for the study design. M.P.P. and E.V. collected the data. M.P.P., I.H.M.S. and E.d.V. contributed to the interpretation of the results. E.V. and J.C.S. revised all analysis critically. M.P.P. drafted the manuscript and the other authors revised it critically. All authors read and approved the final version of the manuscript. Ethics of human subject participation: The study was approved by the Medical Ethical Committee of the VU Medical Centre Amsterdam. Written informed consent was obtained from the participants.

\section{References}

1. Brownell KD \& Horgen KB (2004) Food Fight: The Inside Story of The Food Industry, America's Obesity Crisis, and What We Can Do About It. New York: McGraw-Hill Companies Inc.

2. Rosenkranz RR \& Dzewaltowski DA (2008) Model of the home food environment pertaining to childhood obesity. Nutr Rev 66, 123-140.

3. Lin BH, Guthrie J \& Frazao E (1999) Nutrient contribution of food away from home. In America's Eating Habits: Changes and Consequences Agriculture Information Bulletin no. AIB-750, pp. 213-242 [E Frazao, editor]. Washington, DC: US Department of Agriculture, Economic Research Service.

4. van Berlo I, Huijgen K \& van Aalst M (2011) Consumententrends 2011 (Consumer Trends 2011). http://www.super markt.nl/cblopleidingen/bronnen/Consumententrends2011.pdf (accessed March 2014).

5. van der Bier R (2001) De gekluiside maaltijd (The locked meal). In Report: Vroeger en $\mathrm{Nu}$ (The past and present). http://www.cbs.nl/NR/rdonlyres/D26F2977-0AC5-45DA-92A A-FB57ABF2A1CA/0/index1148.pdf (accessed June 2014).

6. Statline, Centraal Bureau Voor de Statistiek (2012) Vrije tijd; sport, hobby, cultuur, recreatie, vakantie (Leisure time, sports, hobby, culture, recreation and holiday). http://statline. cbs.nl/Statweb/publication/?DM=SLNL\&PA=60029NED\&D1= $50 \& D 2=0-2 \& D 3=a \& V W=T$ (accessed June 2014).

7. Birch LL \& Davison KK (2001) Family environmental factors influencing the developing behavioral controls of food intake and childhood overweight. Pediatr Clin North Am 48, 893-907.

8. Kral TVE \& Rauh EM (2010) Eating behaviors of children in the context of their family environment. Physiol Behav 100, 567-573.

9. Swinburn B, Egger G \& Raza F (1999) Dissecting obesogenic environments: the development and application of a framework for identifying and prioritizing environmental interventions for obesity. Prev Med 29, 563-570.

10. Chandon P \& Wansink B (2002) When are stockpiled products consumed faster? A convenience-salience framework of postpurchase consumption incidence and quantity. J Mark Res 39, 321-335.

11. Ferriday D \& Brunstrom JM (2008) How does foodcue exposure lead to larger meal sizes? Br J Nutr 100, $1325-1332$.

12. van Ittersum K \& Wansink B (2012) Plate size and color suggestibility: the Delboeuf Illusion's Bias on serving and eating behavior. J Consum Res 39, 215-228.

13. Wansink B, van Ittersum K \& Painter JE (2006) Ice cream illusions - bowls, spoons, and self-served portion sizes. $\mathrm{Am}$ J Prev Med 31, 240-243.

14. Campbell KJ, Crawford DA, Salmon J et al. (2007) Associations between the home food environment and obesity-promoting eating behaviors in adolescence. Obesity (Silver Spring) 15, 719-730.

15. Fulkerson JA, Nelson MC, Lytle L et al. (2008) The validation of a home food inventory. Int J Behav Nutr Phys Act 5, 55.

16. Haerens L, Craeynest M, Deforche B et al. (2008) The contribution of psychosocial and home environmental factors in explaining eating behaviours in adolescents. Eur $J$ Clin Nutr 62, 51-59.

17. Cullen KW, Baranowski T, Owens E et al. (2003) Availability, accessibility, and preferences for fruit, $100 \%$ fruit juice, and vegetables influence children's dietary behavior. Health Educ Behav 30, 615-626.

18. Neumark-Sztainer D, Wall M \& Perry C (2003) Correlates of fruit and vegetable intake among adolescents - findings from Project EAT. Prev Med 37, 198-208.

19. Ding D, Sallis JF, Norman GJ et al. (2012) Community food environment, home food environment, and fruit and 
vegetable intake of children and adolescents. J Nutr Educ Behav 44, 634-638.

20. Fedoroff IC, Polivy J \& Herman CP (1997) The effect of preexposure to food cues on the eating behavior of restrained and unrestrained eaters. Appetite 28, 33-47.

21. Marcelino AS, Adam AS \& Couronne T (2001) Internal and external determinants of eating initiation in humans. Appetite 36, 9-14.

22. Poelman MP, de Vet E \& Velema E (2014) Behavioural strategies to control the amount of food selected and consumed. Appetite 72, 156-165.

23. Wansink B (1998) Do we use more when we buy more? The effects of stockpiling on product consumption. Adv Consum Res 25, 21-22.

24. Wansink B (2004) Environmental factors that increase the food intake and consumption volume of unknowing consumers. Annu Rev Nutr 24, 455-479.

25. Rolls BJ, Roe LS, Halverson KH et al. (2007) Using a smaller plate did not reduce energy intake at meals. Appetite 49, 652-660.

26. Wansink B \& van Ittersum K (2006) The visual illusions of food: why plates, bowls, and spoons can bias consumption volume. FASEB J 20, A618.

27. Yip W, Wiessing KR \& Budgett S (2013) Using a smaller dining plate does not suppress food intake from a buffet lunch meal in overweight, unrestrained women. Appetite 69, 102-107.

28. Rozin P, Kabnick K \& Pete E (2003) The ecology of eating: smaller portion sizes in France than in the United States help explain the French paradox. Psychol Sci 14, 450-454.

29. Sobal J \& Wansink B (2007) Kitchenscapes, tablescapes, platescapes, and foodscapes - influences of microscale built environments on food intake. Environ Behav 39. 124-142.

30. Wansink B \& van Ittersum K (2005) Shape of glass and amount of alcohol poured: comparative study of effect of practice and concentration. BMJ 331, 1512-1514.

31. Pratt IS, Croager EJ \& Rosenberg M (2012) The mathematical relationship between dishware size and portion size. Appetite 58, 299-302.

32. Wansink B \& van Ittersum K (2013) Portion size me: plate-size induced consumption norms and win-win solutions for reducing food intake and waste. J Exp Psychol Appl 19, 320-332.

33. US Department of Agriculture (2014) Weight management; Decrease portion size. http://www.choosemyplate.gov/ weight-management-calories/weight-management/betterchoices/decrease-portions.html (accessed January 2014).

34. Akers JD, Estabrooks PA \& Davy BM (2010) Translational research: bridging the gap between long-term weight loss maintenance research and practice. J Am Diet Assoc 110, $1511-1522$.

35. Janiszewski PM \& Ross R (2010) Effects of weight loss among metabolically healthy obese men and women. Diabetes Care 33, 1957-1959.

36. Swinburn BA, Sacks G, Hall KD et al. (2011) The global obesity pandemic: shaped by global drivers and local environments. Lancet 378, 804-814.

37. Poelman MP, de Vet E, Velema E et al. (2014) PORTIONCONTROL@HOME; results of a randomized controlled trial evaluating the effects of a multi-component intervention aimed at portion size on body mass index. Ann Behav Med (Epublication ahead of print version).

38. Voedingscentrum (2013) De Eetmeter (The food measurer). http://mijn.voedingscentrum.nl/nl/eetmeter/2013 (accessed October 2013).

39. IKEA (2014) DINERA Dinnerware. Online Catalogue. http:// www.ikea.com/nl/nl/catalog/products/60057098/ (accessed March 2014)

40. Rijksinstituut voor Volksgezondheid en Milieu (2014) Sociaaleconomische status: Wat is de huidige situatie? (Socio economic status: What is the current situation?). http://www. nationaalkompas.nl/bevolking/sociaaleconomische-status/watis-sociaaleconomische-status/ (accessed March 2014).

41. Condrasky M, Ledikwe JH \& Flood JE (2007) Chefs' opinions of restaurant portion sizes. Obesity (Silver Spring) 15, 2086-2094.

42. Gorin AA, Raynor HA, Fava J et al. (2013) Randomized controlled trial of a comprehensive home environment-focused weight-loss program for adults. Health Psychol 32, 128-137.

43. Haire-Joshu D, Elliott MB, Caito NM et al. (2008) High 5 for Kids: the impact of a home visiting program on fruit and vegetable intake of parents and their preschool children. Prev Med 47, 77-82.

44. Fulkerson JA, Rydell S, Kubik MY et al. (2010) Healthy Home Offerings via the Mealtime Environment (HOME): feasibility, acceptability, and outcomes of a pilot study. Obesity (Silver Spring) 18, 69-74.

45. Stark LJ, Spear S, Boles R et al. (2011) A pilot randomized controlled trial of a clinic and home-based behavioral intervention to decrease obesity in preschoolers. Obesity (Silver Spring) 19, 134-141. 